\title{
Photometric and Interferometric Observations of Recent SAR Arc Events
}

\author{
T. Watanabe and J. S. Kim \\ Department of Atmospheric Science, \\ State University of New York at Albany, \\ Albany, New York 12222, U.S.A. \\ (Received May 7, 1983; Revised December 3, 1983)
}

\begin{abstract}
Photometric and interferometric observations of three SAR arc events, occurring on October 4/5,1980, May 8/9,1981 and October 20/21, 1981, were made at the field station near Albany $\left(42.68^{\circ} \mathrm{N} ; 73.82^{\circ} \mathrm{W}\right)$, New York. The maximum intensities of these arcs are $0.49,0.70$, and $2.0 \mathrm{kR}$, respectively. The peak emission altitude of the intense arc observed on the night of October 20/21, 1981, determined by the triangulation method, was $505 \pm 46 \mathrm{~km}$ at the earlier stage of observation. The temperatures measured within the arc on October 4/5, 1980 are in the range of $1138^{\circ} \mathrm{K}$ to $1475^{\circ} \mathrm{K}$, with an average value of $1349^{\circ} \mathrm{K}$; while for the arc of May $8 / 9$, 1981 they ranged from $1508^{\circ} \mathrm{K}$ to $1840^{\circ} \mathrm{K}$, with an average value of $1697^{\circ} \mathrm{K}$. For the arc of October $20 / 21,1981$, temperatures are in the range of $1379^{\circ} \mathrm{K}$ to $1557^{\circ} \mathrm{K}$, with an average value of $1472^{\circ} \mathrm{K}$. The temperature enhancement within the arc is approximately $200^{\circ} \mathrm{K}$ for the arc observed on October $20 / 21,1981$, and $100^{\circ} \mathrm{K}$ for both the arcs observed on October 4/5, 1980 and on May 8/9, 1981. Our previous measurements on the arc of March 5/6,1981 also show a temperature enhancement of more than $200^{\circ} \mathrm{K}$ within the arc (WATANABE and KIM, 1982). These temperature enhancements clearly exceeded those predicted by a 2-dimensional model calculation.

The present results also show that the temperature enhancement within the arc is strongly correlated with the overall maximum intensity of the arc. When the maximum intensity of the arc reaches about $400 R$, the temperatures within the arc are variable (see OKANO and KIM, 1979), but the temperature enhancement within the arc becomes almost always detectable. However, when the overall maximum intensity of the arc reaches about $2 \mathrm{k} R$, the temperature within the arc is quite stable and the temperature enhancement within the arc is quite substantial.
\end{abstract}

\section{Introduction}

Since the discovery of stable auroral red arcs (SAR arcs) by Barbier in 1956 from Haute Provence in southern France (BARBIER, 1958), many workers have reported a number of SAR arcs that were observed during the past three solar activity maximum periods (i.e., these periods cover several years each that are centered at 1957-58, 1968-69, and 1979-80). 
During the 1957-58 solar activity maximum, no attempt was made to measure the neutral gas temperature within the SAR arc. However, during the 1968-69 solar activity maximum, the neutral gas temperature within and in the near vicinity of an SAR arc was measured (using Fabry-Perot spectrometers) by RoBLE et al. (1970) for the October 31/Nobember 1, 1968 SAR arc and by HeRNANDEZ (1972) for the March 8/9, 1970 SAR arc. RoBle et al. (1970) found no measurable temperature increase $\left(<75^{\circ} \mathrm{K}\right)$ within the SAR arc compared with the region outside the arc. However, HERNANDEZ (1972) measured a $100^{\circ} \mathrm{K}$ temperature increase in the March 8/9, 1970 SAR arc. During the present solar activity maximum, we have systematically measured the neutral gas temperature within and in the near vicinity of an SAR arc. On the night of September 25/26, 1978 OKANO and KIM (1979) observed a distinct SAR arc, using a multicolar meridian scanning photometer and a Fabry-Perot interferometer. The temperatures within the arc showed an increase of about $200^{\circ} \mathrm{K}$ at approximately 2.7 hours after the appearance of the arc, while no other enhancement of the temperature was observed during the observation period. On the night of March 5/6, 1981, at a field station near Albany, New York $\left(42.68^{\circ} \mathrm{N}\right.$; $73.82^{\circ} \mathrm{W}$ ), a most extraordinary SAR arc was observed (WATANABE and KIM, 1982). The arc was the most intense arc $(\sim 2.2 \mathrm{k} R)$ ever observed at Albany, NY during the past twelve years. The temperatures within the arc were quite stable with respect to time, even during the period of very rapid and large decrease in the arc intensity. The difference between the temperatures within the arc and those outside the arc was not only considerably greater than the value predicted by the 2-dimensional model calculation of the SAR arc (RoBLE and Dickinson, 1970; REES and Roble, 1975), but also much greater than any other observed value previously reported (WATANABE and KIM, 1982).

In this paper we describe the results of the photometric and interferometric measurements of the three SAR arcs observed at Albany, New York on the nights of October 4/5,1980, May 8/9,1981, and October 20/21, 1981. The measurements of the SAR arc were made with both a multicolor meridian scanning photometer and a 6inch high-resolution Fabry-Perot interferometer. Since detailed descriptions of the instruments used for observations and the method of data analysis are given previously by OKANO and KIM (1979) and OKANO et al. (1980), they are not repeated here.

\section{Results for Observations}

\subsection{October 4/5, 1980 arc event}

On the night of October 4/5, 1980 a strong, stable auroral red arc was observed from the field station near Albany, New York. The photometric and interferometric observations began at 1900 EST and 2011 EST, respectively, on October 4, 1980. The photometer immediately detected a distinct SAR arc. The position of the arc appeared at $50^{\circ}$ north of the station at the beginning of the observation $(\sim 1907$ EST), and then the arc moved southward throughout the observation period, reaching $20^{\circ} \mathrm{S}$ near the end of the observation (2300 EST). 
The peak intensity, reduced to zenith values of the arc over the background $6300 \AA$ emission, was measured from the photometer records and plotted against Eastern Standard Time (and Universal Time) in Fig. 1. The time histories of $D_{\text {st }}$ values and $K_{\mathrm{p}}$ indices for October $4 / 5,1980$ are shown in Fig. 2 . The intensity of the [OI] $6300 \AA$ emission was $120 R$ at 1907 EST, and grew rapidly at the beginning of the observation. The intensity reached its maximum value of $490 R$ at 2105 EST on October 4, 1980 (0205 UT on October 5, 1980), and then slowly decreased to $300 R$ at 2347 EST when the observation was terminated because of increasing cloudiness. Using the zenith angles of the position of the peak intensity, and assuming the altitude of the arc to be $400 \mathrm{~km}$ (OLD et al., 1972; ROACH and ROACH, 1963), the average speed and the half-max intensity width of the arc were calculated. The calculated average southward speed of the arc was $200 \mathrm{~km} / \mathrm{h}$ and $56 \mathrm{~km} / \mathrm{h}$ before and after $2100 \mathrm{EST}$, respectively, and the half-max intensity widths ranged from $90 \mathrm{~km}$ to $140 \mathrm{~km}$. The position of the peak intensity was transformed into $L$ value intercepts at $400 \mathrm{~km}$, and the calculated $L$ values varied from 3.8 at 1907 EST to 2.9 at 2315 EST. The visible aurora was not seen from the field station during the observation.

The temperatures measured on the night of October 4/5, 1981 are tabulated in Table 1. The field of view of the interferometer was directed to either the position of peak intensity of the arc or outside the arc at zenith angles of $30^{\circ} \mathrm{S}$ and $70^{\circ} \mathrm{N}$. The temperatures obtained from the northern sky at the zenith angle of $70^{\circ} \mathrm{N}\left(T_{70 \mathrm{~N}}\right)$, at the beginning and near the end of the observation, show a steady decrease of $T_{70 \mathrm{~N}}$ from $\sim 1300^{\circ} \mathrm{K}$ to $\sim 1000^{\circ} \mathrm{K}$ during this period. The temperatures measured within the $\operatorname{arc}\left(T_{\mathrm{A}}\right)$ were in the range of $1138^{\circ}$ to $1475^{\circ} \mathrm{K}$ and showed considerable fluctuation. Averages of $T_{70 \mathrm{~N}}, T_{\mathrm{A}}$, and $T_{30 \mathrm{~s}}$ are also given in Table 1 . These averages show that the average $T_{\mathrm{A}}$ value is about $100^{\circ} \mathrm{K}$ higher than the average $T_{30 \mathrm{~s}}$.

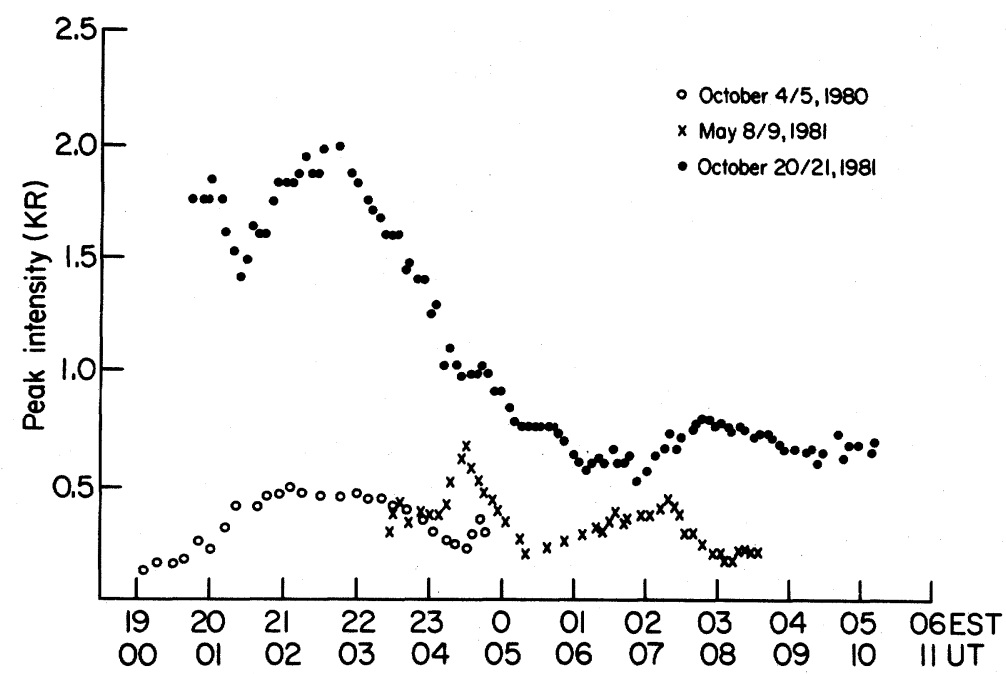

Fig. 1. Peak intensities of the SAR arc, reduced to zenith values over the background $6300 \AA$ emission as a function of time. 


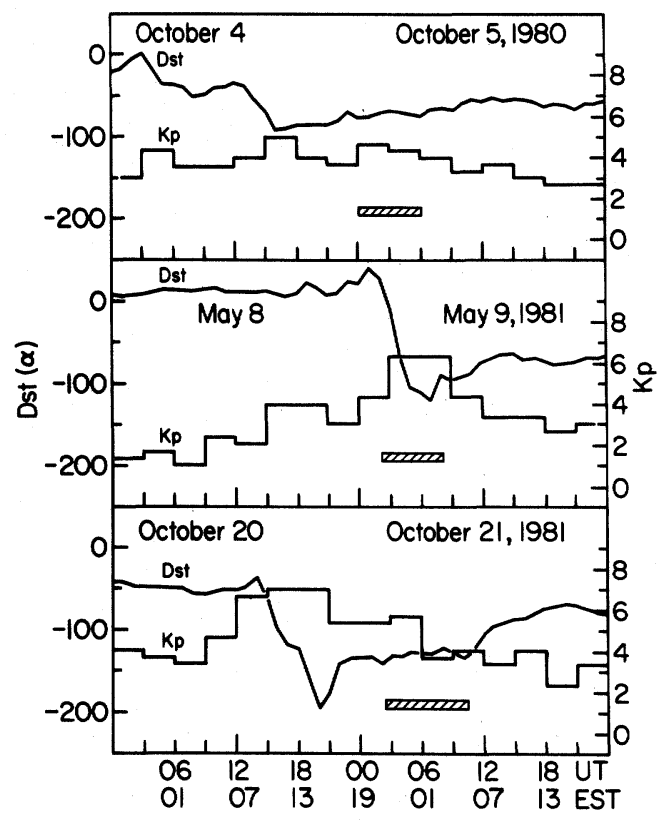

Fig. 2. Three hourly planetary geomagnetic indices $K_{\mathrm{p}}$ and values of $D_{\mathrm{st}}$ for three SAR events on October 4/5, 1980, May 8/9, 1981, and October 20/21, 1981. The observation periods for interferometric measurement are indicated by shaded areas.

\subsection{May 8/9, 1981 arc event}

The photometric and interferometric observation of the SAR arc was carried out on the night of May 8/9, 1981. At the beginning of the observation (2225 EST), the photometer detected the SAR arc at the zenith angle of $3^{\circ} \mathrm{S}$. The arc moved southward, reaching $51^{\circ} \mathrm{S}$ at around $0130 \mathrm{EST}$, reversed its direction of motion and then remained between $42^{\circ} \mathrm{S}$ and $46^{\circ} \mathrm{S}$ until the end of the observation at $0335 \mathrm{EST}$. The peak intensity, reduced to zenith values of the arc, was measured from the photometer records and plotted against Eastern Standard Time (and Universal Time) in Fig. 1. The intensities of the [OI] $6300 \AA$ emission were between $300 R$ and $430 R$ at the beginning of the observation (2227-2243 EST). The intensity reached its maximum of $700 R$ at $2330 \mathrm{EST}$, decreased to $230 R$ at $0020 \mathrm{EST}$, and then remained between $220 R$ and $450 R$ during the rest of the observation. The observation was terminated at 0335 EST. The average southward speed of the arc was $140 \mathrm{~km} / \mathrm{h}$ before $0130 \mathrm{EST}$, and the movement of the arc was very small after $0130 \mathrm{EST}$. Very intense visible aurora was observed in the northern sky until about 0200 EST.

The temperatures measured on the night of May 8/9, 1981 are tabulated in Table 2. The field of view of the interferometer was directed to either the position of the peak intensity of the arc or outside the arc at zenith angles of $70^{\circ} \mathrm{S}$ and $70^{\circ} \mathrm{N}$. The temperatures measured within the $\operatorname{arc}\left(T_{\mathrm{A}}\right)$ were in the range of $1508^{\circ} \mathrm{K}$ to $1840^{\circ} \mathrm{K}$, 
Table 1. Neutral temperature derived from the [OI] $6300 \AA$ line profiles observed on the night of October $4 / 5,1980$.

\begin{tabular}{|c|c|c|c|c|c|}
\hline Group & $\begin{array}{l}\text { Zenith } \\
\text { angle } \\
\text { (Deg) }\end{array}$ & $\begin{array}{l}\text { Time } \\
(\mathrm{EST})\end{array}$ & $\begin{array}{l}\text { Accumulation } \\
\text { time per } \\
\text { fringe } \\
\text { (min) }\end{array}$ & $\begin{array}{c}\text { Temperature } \\
\left({ }^{\circ} \mathrm{K}\right)\end{array}$ & $\begin{array}{c}\text { Group } \\
\text { average } \\
\left({ }^{\circ} \mathrm{K}\right)\end{array}$ \\
\hline $\begin{array}{l}\text { Outside } \\
\text { the Arc }\end{array}$ & $\begin{array}{l}70 \mathrm{~N} \\
70 \mathrm{~N} \\
70 \mathrm{~N} \\
70 \mathrm{~N} \\
70 \mathrm{~N} \\
70 \mathrm{~N} \\
70 \mathrm{~N} \\
70 \mathrm{~N} \\
70 \mathrm{~N} \\
70 \mathrm{~N}\end{array}$ & $\begin{array}{l}2011 \\
2021 \\
2036 \\
2046 \\
2250 \\
2300 \\
2317 \\
2321 \\
2330 \\
2334\end{array}$ & $\begin{array}{l}5 \\
5 \\
5 \\
5 \\
5 \\
5 \\
2 \\
2 \\
2 \\
2\end{array}$ & $\begin{array}{l}1327 \pm 16 \\
1401 \pm 27 \\
1365 \pm 28 \\
1319 \pm 28 \\
1105 \pm 32 \\
1104 \pm 25 \\
1019 \pm 25 \\
1019 \pm 25 \\
1085 \pm 25 \\
1079 \pm 26\end{array}$ & 1182 \\
\hline $\begin{array}{l}\text { Within } \\
\text { the Arc }\end{array}$ & $\begin{array}{l}0 \\
0 \\
0 \\
0 \\
0 \\
0 \\
5 \mathrm{~S}\end{array}$ & $\begin{array}{l}2110 \\
2120 \\
2138 \\
2148 \\
2203 \\
2213 \\
2238\end{array}$ & $\begin{array}{l}5 \\
5 \\
5 \\
5 \\
5 \\
5 \\
5\end{array}$ & $\begin{array}{l}1343 \pm 37 \\
1350 \pm 38 \\
1442 \pm 45 \\
1461 \pm 53 \\
1138 \pm 40 \\
1236 \pm 47 \\
1475 \pm 68\end{array}$ & 1349 \\
\hline $\begin{array}{l}\text { Outside } \\
\text { the Arc }\end{array}$ & $\begin{array}{l}30 S \\
30 S\end{array}$ & $\begin{array}{l}2227 \\
2232\end{array}$ & $\begin{array}{l}5 \\
5\end{array}$ & $\begin{array}{l}1240 \pm 47 \\
1235 \pm 45\end{array}$ & 1238 \\
\hline
\end{tabular}

with an average value of $1697^{\circ} \mathrm{K}$. The average $T_{\mathrm{A}}$ value is about $90^{\circ} \mathrm{K}$ higher than the average $T_{70 \text { s }}$ (Table 2).

\subsection{October 20/21, 1981 arc event}

An SAR arc, with very strong intensity, was simultaneously observed on the night of October $20 / 21,1981$ from two stations-Albany $\left(42.68^{\circ} \mathrm{N} ; 73.82^{\circ} \mathrm{W}\right)$ and Plattsburgh $\left(44.70^{\circ} \mathrm{N} ; 73.48^{\circ} \mathrm{W}\right)$, New York.

The position and peak intensity of the arc were measured with a meridian scanning photometer at both Albany and Plattsburgh, and the neutral temperatures within and outside the arc were measured by a Fabry-Perot interferometer at Albany.

The photometric observation at Albany began at 1926 EST and interferometric observation at $2031 \mathrm{EST}$; the sky had been very clear throughout the night. At Plattsburgh, the photometric observation began at 1820 EST, and the sky condition 
Table 2. Neutral temperature derived from the [OI] $6300 \AA$ line profiles observed on the night of May 8/9, 1981.

\begin{tabular}{|c|c|c|c|c|c|}
\hline Group & $\begin{array}{l}\text { Zenith } \\
\text { angle } \\
(\mathrm{Deg})\end{array}$ & $\begin{array}{l}\text { Time } \\
\text { (EST) }\end{array}$ & $\begin{array}{l}\text { Accumulation } \\
\text { time per } \\
\text { fringe } \\
\text { (min) }\end{array}$ & $\begin{array}{c}\text { Temperature } \\
\left({ }^{\circ} \mathrm{K}\right)\end{array}$ & $\begin{array}{c}\text { Group } \\
\text { average } \\
\left({ }^{\circ} \mathrm{K}\right)\end{array}$ \\
\hline $\begin{array}{l}\text { Outside } \\
\text { the Arc }\end{array}$ & $\begin{array}{l}70 \mathrm{~N} \\
70 \mathrm{~N} \\
70 \mathrm{~N} \\
70 \mathrm{~N} \\
70 \mathrm{~N} \\
70 \mathrm{~N} \\
70 \mathrm{~N} \\
70 \mathrm{~N} \\
70 \mathrm{~N} \\
70 \mathrm{~N} \\
70 \mathrm{~N} \\
70 \mathrm{~N} \\
70 \mathrm{~N}\end{array}$ & $\begin{array}{l}2236 \\
2253 \\
2257 \\
2305 \\
2309 \\
0037 \\
0041 \\
0050 \\
0054 \\
0312 \\
0316 \\
0324 \\
0323\end{array}$ & $\begin{array}{l}2 \\
2 \\
2 \\
2 \\
2 \\
2 \\
2 \\
2 \\
2 \\
2 \\
2 \\
2 \\
2\end{array}$ & $\begin{array}{l}1527 \pm 21 \\
1654 \pm 20 \\
1759 \pm 25 \\
1663 \pm 28 \\
1816 \pm 34 \\
1440 \pm 20 \\
1441 \pm 23 \\
1523 \pm 29 \\
1508 \pm 29 \\
1543 \pm 22 \\
1640 \pm 20 \\
1602 \pm 25 \\
1658 \pm 25\end{array}$ & 1544 \\
\hline $\begin{array}{l}\text { Within } \\
\text { the Arc }\end{array}$ & $\begin{array}{l}45 \mathrm{~S} \\
45 \mathrm{~S} \\
45 \mathrm{~S} \\
45 \mathrm{~S}\end{array}$ & $\begin{array}{l}0206 \\
0210 \\
0221 \\
0225\end{array}$ & $\begin{array}{l}2 \\
2 \\
2 \\
2\end{array}$ & $\begin{array}{l}1508 \pm 49 \\
1840 \pm 67 \\
1809 \pm 76 \\
1633 \pm 73\end{array}$ & 1697 \\
\hline $\begin{array}{l}\text { Outside } \\
\text { the Arc }\end{array}$ & $\begin{array}{l}70 S \\
70 S \\
70 S \\
70 S \\
70 S \\
70 S \\
70 S \\
70 S \\
70 S \\
70 S\end{array}$ & $\begin{array}{l}2318 \\
0009 \\
0103 \\
0107 \\
0115 \\
0119 \\
0236 \\
0240 \\
0249 \\
0259\end{array}$ & $\begin{array}{r}10 \\
10 \\
2 \\
2 \\
2 \\
2 \\
2 \\
2 \\
5 \\
5\end{array}$ & $\begin{array}{l}1577 \pm 52 \\
1622 \pm 44 \\
1477 \pm 68 \\
1546 \pm 74 \\
1636 \pm 71 \\
1709 \pm 78 \\
1536 \pm 143 \\
1660 \pm 161 \\
1733 \pm 115 \\
1581 \pm 97\end{array}$ & 1609 \\
\hline
\end{tabular}

was fair. However, due to frequent mechanical malfunction of the photometer, the observation at Plattsburgh was terminated at 2045 EST.

The photometers at both stations detected the SAR arc immediately after the observations began. The arc appeared and remained in the southern sky throughout the night for both stations. The positions of the arc in zenith angle slowly changed from $40^{\circ} \mathrm{S}$ to $66^{\circ} \mathrm{S}$ throughout the night at Albany. Visible aurora appeared several 
times in the northern sky at both stations; as the visible aurora was always far in the northern sky, it was well separated from the SAR arc. The intensity of the SAR arc reached its maximum of $2 \mathrm{k} R$ around $2130 \mathrm{EST}$, and then decreased rapidly to $700 R$ within four hours (Fig. 1).

The interferometer was directed toward the SAR arc to measure the [OI] $6300 \AA$ line profiles from the arc. The measurements were also taken from both northern $\left(70^{\circ} \mathrm{N}\right)$ and southern $\left(70^{\circ} \mathrm{S}\right)$ skies to measure background temperature.

The temperatures measured within and outside the arc during the night are tabulated in Table 3 and also shown in Fig. 3. The temperature within the arc, $T_{\mathrm{A}}$, was very stable $\left(1470 \pm 80^{\circ} \mathrm{K}\right)$ throughout the night, even though the arc intensity decreased from $2 \mathrm{k} R$ to $700 R$. The temperature outside the arc, $T_{70 \mathrm{~s}}$, taken from $70^{\circ} \mathrm{S}$ was also stable during the night. As can be seen in Fig. 3, $T_{\mathrm{A}}$ 's are clearly higher than $T_{70 \mathrm{~s}}$ 's. Indeed, the average value of $T_{\mathrm{A}}$ 's throughout the observation period is $\sim 200 \mathrm{~K}$ higher than the average value of $T_{70 \text { s }}$ (Table 3 ).

The altitude of the position of the peak intensity was determined by using triangulation for the photometric data taken both at Albany and Plattsburgh. Calculated altitude of the arc, $h$, is $505 \pm 46 \mathrm{~km}$ at 2024 EST.

\section{Discussion}

Results of photometric and interferometric measurements of three SAR arcs occurring on October 4/5, 1980, May 8/9, 1981 and October 20/21, 1981 are reported in this paper. The maximum intensities of these arcs are $0.49,0.70$, and $2.0 \mathrm{k} R$, respectively. The temperatures measured within the arc on the night of October $4 / 5$, 1980 are in the range of $1138^{\circ} \mathrm{K}$ to $1475^{\circ} \mathrm{K}$, with an average value of $1349^{\circ} \mathrm{K}$; while for the arc of May $8 / 9,1981$ they ranged from $1508^{\circ} \mathrm{K}$ to $1840^{\circ} \mathrm{K}$, with an average value of $1697^{\circ} \mathrm{K}$. For the arc of October 20/21, 1981, temperatures are in the range of $1379^{\circ} \mathrm{K}$ to $1557^{\circ} \mathrm{K}$, with an average value of $1472^{\circ} \mathrm{K}$.

The altitude of the intense arc observed on the night of October 20/21, 1981 was determined by the triangulation method. The derived altitude was $505 \pm 46 \mathrm{~km}$ at the earlier stage of the observation; this altitude is much higher than that previously obtained at the same stations by Okano (private communication, 1983), who observed at $70 R$ arc on the altitude of $400 \mathrm{~km}$ on September 26/27, 1979. During the 1968-69 solar activity maximum period, OLD et al. $(1971 ; 1972)$ observed a multiple arc on the night of March 8/9,1970. This multiple arc consisted of two $6300 \AA$ arcs for most of the observing time. The intensity of the more northerly arc of the two was only about $80 R$ at $0100 \mathrm{UT}$ (2000 EST) and the corresponding height of the maximum intensity of this arc was found to be $405 \mathrm{~km}$. The average height for the night was $394.5 \mathrm{~km}$, with a standard deviation of $15.0 \mathrm{~km}$. On the same night, measurements by HeRnandez (1972) from the Fritz Peak Observatory, Colorado showed the height of the arc (we believe that this arc is the more southerly arc of the two) to be about $500 \mathrm{~km}$ for most of the observation, decreasing at the end of the observation to about $400 \mathrm{~km}$. The intensity of the arc was about $1.5 \mathrm{k} R$ at the beginning of the night, decreasing to about $250-300 R$ later in the evening. 
Table 3. Neutral temperatures derived from the [OI] $6300 \AA$ line profiles observed on the night of October 20/21, 1981.

\begin{tabular}{|c|c|c|c|c|c|}
\hline Group & $\begin{array}{l}\text { Zenith } \\
\text { angle } \\
\text { (Deg) }\end{array}$ & $\begin{array}{l}\text { Time } \\
\text { (EST) }\end{array}$ & $\begin{array}{l}\text { Accumulation } \\
\text { time per } \\
\text { fringe } \\
\text { (min) }\end{array}$ & $\begin{array}{c}\text { Temperature } \\
\left({ }^{\circ} \mathrm{K}\right)\end{array}$ & $\begin{array}{c}\text { Group } \\
\text { average } \\
\left({ }^{\circ} \mathrm{K}\right)\end{array}$ \\
\hline $\begin{array}{l}\text { Outside } \\
\text { the Arc }\end{array}$ & $\begin{array}{l}70 \mathrm{~N} \\
70 \mathrm{~N} \\
70 \mathrm{~N} \\
70 \mathrm{~N} \\
70 \mathrm{~N} \\
70 \mathrm{~N}\end{array}$ & $\begin{array}{l}2155 \\
2159 \\
2209 \\
2213 \\
0200 \\
0213\end{array}$ & $\begin{array}{l}2 \\
2 \\
2 \\
2 \\
2 \\
5\end{array}$ & $\begin{array}{l}1466 \pm 22 \\
1423 \pm 21 \\
1486 \pm 22 \\
1461 \pm 23 \\
1228 \pm 77 \\
1300 \pm 65\end{array}$ & . \\
\hline $\begin{array}{l}\text { Within } \\
\text { the Arc }\end{array}$ & $\begin{array}{l}49 \mathrm{~S} \\
49 \mathrm{~S} \\
49 \mathrm{~S} \\
53 \mathrm{~S} \\
53 \mathrm{~S} \\
53 \mathrm{~S} \\
53 \mathrm{~S} \\
53 \mathrm{~S} \\
53 \mathrm{~S} \\
50 \mathrm{~S} \\
50 \mathrm{~S} \\
50 \mathrm{~S} \\
50 \mathrm{~S} \\
50 \mathrm{~S} \\
60 \mathrm{~S} \\
60 \mathrm{~S}\end{array}$ & $\begin{array}{l}2035 \\
2044 \\
2048 \\
2223 \\
2227 \\
2237 \\
2241 \\
2250 \\
2254 \\
0020 \\
0024 \\
0039 \\
0050 \\
0054 \\
0355 \\
0405\end{array}$ & $\begin{array}{l}2 \\
2 \\
2 \\
2 \\
2 \\
2 \\
2 \\
2 \\
2 \\
2 \\
2 \\
2 \\
2 \\
2 \\
5 \\
5\end{array}$ & $\begin{array}{l}1542 \pm 39 \\
1527 \pm 35 \\
1503 \pm 33 \\
1442 \pm 30 \\
1506 \pm 32 \\
1424 \pm 32 \\
1446 \pm 33 \\
1496 \pm 36 \\
1461 \pm 36 \\
1531 \pm 54 \\
1457 \pm 50 \\
1379 \pm 53 \\
1438 \pm 60 \\
1386 \pm 62 \\
1456 \pm 41 \\
1557 \pm 43\end{array}$ & 1472 \\
\hline $\begin{array}{l}\text { Outside } \\
\text { the Arc }\end{array}$ & $\begin{array}{c}70 \mathrm{~S} \\
70 \mathrm{~S} \\
70 \mathrm{~S} \\
70 \mathrm{~S} \\
70 \mathrm{~S} \\
70 \mathrm{~S} \\
70 \mathrm{~S} \\
70 \mathrm{~S} \\
70 \mathrm{~S} \\
70 \mathrm{~S}\end{array}$ & $\begin{array}{l}2058 \\
2125 \\
2303 \\
2313 \\
0005 \\
0104 \\
0128 \\
0304 \\
0505 \\
0515\end{array}$ & $\begin{array}{l}5 \\
5 \\
5 \\
5 \\
5 \\
5 \\
5 \\
5 \\
5 \\
5\end{array}$ & $\begin{array}{l}1369 \pm 55 \\
1344 \pm 57 \\
1191 \pm 96 \\
1323 \pm 113 \\
1233 \pm 123 \\
1276 \pm 97 \\
1176 \pm 80 \\
1343 \pm 131 \\
1237 \pm 64 \\
1169 \pm 53\end{array}$ & 1266 \\
\hline
\end{tabular}




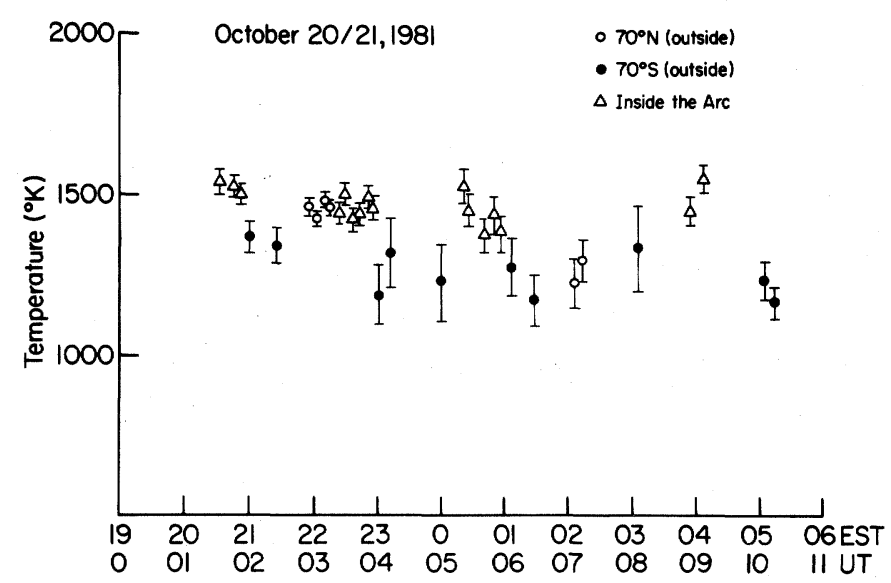

Fig. 3. Neutral temperatures derived from the [OI] $6300 \AA$ line profiles observed on the night of October 20/21, 1981.

These results indicate that there is a tendency to observe intense arcs at higher altitude and weak ones at lower altitude. This tendency may be partly due to the height distribution of electron concentration in the atmosphere. The [OI] $6300 \AA$ height of peak emission was reported to be strongly correlated with the peak electron concentration (HERNANDEZ, 1972).

The temperature enhancement within the arc is approximately $200^{\circ} \mathrm{K}$ for the arc observed on October $20 / 21,1981$, and $100^{\circ} \mathrm{K}$ for both the arc observed on October $4 / 5,1980$ and that observed on May 8/9,1981. Our previous measurements for the arc of March 5/6, 1981 also show a temperature enhancement of more than $200^{\circ} \mathrm{K}$ within the arc (WATANABE and KIM, 1982). These temperature enhancements clearly exceeded those predicted by the 2-dimensional model calculation reported by ROBLE and Dickinson (1970). In light of these temperature results and of those for other recent arc events (OKANO and KIM, 1979; WATANABE and KIM, 1982), modifications of the existing heat conduction model may be required.

Although the intensity of the arc observed on October 20/21, 1981 varied considerably from $2 \mathrm{k} R$ to $700 R$, the temperature within the arc remained constant. In our previous measurements for the arc of March 5/6,1981, we also found that the temperatures within the arc are approximately constant at $1300^{\circ} \mathrm{K}$, while the arc intensity changed from $2.2 \mathrm{k} R$ to $300 R$ (WATANABE and KIM, 1982), indicating that the time constant for energy loss is very large.

Although the temperature enhancements within the arc were previously measured experimentally (HeRnANDEZ, 1972; OKANO and KIM, 1979; WATANABE and KIM, 1982), very large temperature enhancements measured on the $2 \mathrm{k} R$ arc of October 20/21, 1981 are clearly the most interesting results. The fact that the temperature in the arc region observed on October 20/21, 1981 remained constant throughout the night implies that the energy input and energy loss is balanced. 
The present results show that the temperature enhancement within the arc is strongly correlated with the overall maximum intensity of the arc. When the maximum intensity of the arc reaches about $400 R$, the temperatures within the arc are variable (OKANO and KIM, 1979, but the temperature enhancement within the arc becomes almost always detectable. However, when the maximum intensity of the arc reaches about $2 \mathrm{k} R$, the temperature within the arc is quite stable and the temperature enhancement within the arc is quite substantial.

The work reported here has been supported jointly by the National Science Foundation and the Air Force Office of Scientific Research (ATM 78-05739).

\section{REFERENCES}

BARBIER, D., The auroral activity of low latitudes, Ann. Geophys., 14, 334-355, 1958.

Hernandez, G., Spectroscopic studies of the arc of March 8/9, 1970, Planet, Space Sci., 20, 1309-1321, 1972.

OKano, S. and J. S. KIM, Photometric and interferometric observations of the SAR arc event of September 25/26, 1978, J. Geophys. Res., 84, 4441-4445, 1979.

OKano, S., J. S. KIM, and T. ICHIKaWA, Design of a multiple-zone aperture and application to a FabryPerot interferometer, Appl. Opt., 19, 1622-1629, 1980.

Old, T., M. OKudA, and J. S. KIM, Reappearance of a multiple mid-latitude auroral arc (6300 $)$, Nature, 231, 14-17, 1971.

Old, T., M. OKUDA, and J. S. KIM, Observation of an unusual multiple midlatitude $6300 \AA$ (OI) arc from two ground stations, Ann. Geophys., 28, 863-869, 1972.

ReEs, M. H. and R. G. Roble, Observations and theory of the formation of stable auroral red arcs, Rev. Geophys. Space Phys., 13, 201-242, 1975.

RoACH, F. E. and J. R. RoACH, Stable $6300 \AA$ auroral arcs in midlatitudes, Planet. Space Sci., 11, 523-545, 1963.

Roble, R. G., P. B. HaYs, and A. F. NAGY, Photometric and interferometric observations of a midlatitude stable auroral red arc, Planet. Space Sci., 18, 431-439, 1970.

Roble, R. G. and R. E. Dickinson, Atmospheric response to heating within a stable auroral red arc, Planet. Space Sci., 18, 1489-1498, 1970.

WatANABE, T. and J. S. Kim, Photometric and interferometric observations of the SAR arc event of March 5/6, 1981, Geophys. Res. Lett., 9, 64-67, 1982. 